\title{
Regulation of nuclear shape and size in plants
}

Iris Meier*, Anna H.N. Griffis, Norman R. Groves, and Alecia Wagner

Department of Molecular Genetics, The Ohio State University, 520 Aronoff Laboratory, 318 W. $12^{\text {th }}$ Avenue, Columbus, OH 43210, USA

*corresponding author: meier.56@osu.edu; 614-292-8323; Fax: 614-292-6345

\begin{abstract}
Nuclear shape and size changes have long been used by cytopathologists to diagnose, stage, and prognose cancer. However, the underlying causalities and molecular mechanisms are largely unknown. The current eukaryotic tree of life groups eukaryotes into five supergroups, with all organisms between humans and yeast falling into the supergroup Opisthokonta. The emergence of model organisms with strong molecular genetic methodology in the other supergroups has recently facilitated a broader evolutionary approach to pressing biological questions. Here, we review what is known about the control of nuclear shape and size in the Archaeplastidae, the supergroup containing the higher plants. We discuss common themes as well as differences towards a more generalized model of how eukaryotic organisms regulate nuclear morphology.
\end{abstract}




\section{Introduction}

In animals, changes in nuclear shape and size are associated with cell differentiation, development, and disease (recently reviewed by [1]). Cancer cell nuclear morphology is often altered, but the cause is not well understood [2,3]. In addition, changes in nuclear morphology are associated with several laminopathies and nuclear envelopathies $[4,5]$. Thus, understanding the physiological relevance and mechanism of nuclear morphology regulation is a topic of fundamental cell biology with potentially high translational impact. In animal model systems, nuclear size and shape are influenced by DNA ploidy, nuclear structural components, cytoplasmic factors, nucleocytoplasmic transport, the cytoskeleton, and the extracellular matrix [3]. It is becoming increasingly evident that mitotic events also influence nuclear morphology [1]. However, our understanding of how nuclear shape and size are regulated is rather poor and our knowledge of the role that nuclear shape plays in nuclear function is limited [6].

The Archaeplastidae and Opisthokonta separated roughly one billion years ago as singlecelled organisms [7]. While the fairly late recognition of the vastness of separate evolution has hampered fundamental plant cell biology research for a couple of decades, recent discoveries about how plants "solve" shared cellular problems in different ways promise to enlighten research in all model organisms by introducing a broader evolutionary perspective. Here, we review what is known about nuclear size and shape regulation in plants, discuss the first emerging molecular players, and compare and contrast them to their opisthokont counterparts.

\section{Nuclear size and shape in plants}

Embryonic and meristem nuclei in flowering plants are nearly spherical. During cell and tissue differentiation, however, nuclei adopt a variety of elongated and super-elongated shapes and increase their size, correlated to endoreplication [8]. In Arabidopsis thaliana, nuclei range from spherical in meristems and guard cells to hyper-elongated with extended membrane tails in root hairs $[9,10 \bullet \bullet]$. Some nuclei even divide into multiple sub-nuclear structures connected by thread-like projections [11] (Fig. 1).

Elongated nuclei typically correlate with elongated cells. Nuclear size roughly correlates with cell size, with the smallest leaf nuclei in the diploid guard cells, bigger nuclei in 
epidermal cells, and the biggest nuclei in the large, highly polyploid unicellular trichomes [12].

The haploid pollen grain is the plant male gametophyte. An Arabidopsis pollen grain contains three nuclei: the vegetative nucleus (VN) of the pollen cell and the two nuclei of the embedded germ cells (GCs). While the GC nuclei are small and spherical and contain highly condensed chromatin, the VN is larger and narrows during pollen tube growth, becoming oval to spindle-shaped, and has reduced chromatin compaction $[13,14,15,16]$. Nuclear size and volume decrease during seed maturation and increase again during imbibition and germination of Arabidopsis seeds. This correlates not with passive water uptake, but rather with heterochromatin distribution [17••]. There is, however, no clear correlation between nuclear size changes and seed dormancy or desiccation tolerance. Several mutants with defects in seed dormancy undergo wildtype-like nuclear size changes [17••]. Also, a crwn1 crwn2 mutant (see below) that has imbibition and germinationinsensitive small nuclei has no germination or dormancy defects. This suggests that specific properties of nuclei are an adaptation to desiccation, but independent of dormancy.

Several other studies have observed changes in seed nuclear size. Phaseolus vulgaris seed pith and plumule cell nuclei shrink when they approach the dormant phase [18]. Phaseolus lunatis and Zea mays have smaller nuclei in dormant pith, cortex, and vascular cells of the seed [19], and an Arabidopsis study suggests a correlation between nuclear size and both low transcription rates and water loss in seeds [20]. Aside from seeds, Craterostigma plantarum (the "resurrection plant") leaf nuclei were shown to shrink to about half size upon desiccation $[17 \bullet \bullet]$. Because osmotic stress has been shown to reduce nuclear size [21], seed or plant desiccation might provide an experimental system to dissect this aspect in a whole-tissue context.

\section{Nuclear shape and plant lamin-like proteins}

In humans, mice, and flies, lamin mutations cause aberrantly elongated nuclei in heart tissue [22]. In Hutchinson-Gilford Progeria Syndrome - a laminopathy - nuclei form blebs and protrusions from the nuclear surface, and have altered mechanical properties [22,23]. Lamin B overexpression causes nuclear blebs and misshapen nuclei and additional intranuclear membranes, while Lamin B depletion reduces nuclear size [1]. 
Plant genomes do not encode homologs of the animal lamins, but a filamentous meshwork adjacent to the inner nuclear membrane (INM) can be observed by electron microscopy [24]. Nuclear matrix component protein 1 (NMCP1) and its Arabidopsis homologs CROWDED NUCLEI (CRWN) 1, CRWN2, CRWN3, and CRWN4 are currently the best candidates for lamin analogs in plants [25,26]. NMCP1 has a central long coiled-coil domain, short N- and C- terminal non-helical domains, and a predicted nuclear localization signal (NLS) in the C-terminal domain. An anti-NMCP1 antibody decorates the nuclear envelope (NE) in both light and electron microscopy and the protein fractionates with the insoluble nucleoskeleton fraction [27•]. These features are similar to lamins, but NMCP1 is about twice the size of human lamin A and has no sequence similarity to lamins [28]. Arabidopsis CRWN1 and CRWN4 are located at the nuclear periphery while CRWN2 and CWN3 are in the nuclear interior (Fig. 2) [26,29••,30••]. Some CRWN mutant combinations lead to severely dwarfed plants with smaller cells, and a quadruple knockout mutant is lethal [30••]. At the cellular level, the most prominent $C R W N$ mutant phenotype is a significant nuclear size reduction and increased nuclear circularity. crwn2 or crwn3 alone do not affect nuclear morphology, but enhance crwn1 and crwn4 mutant phenotypes. CRWN mutant nuclei also have fewer chromocenters, suggesting defects in heterochromatin organization. No changes in ploidy were observed [29••]. Overexpression of CRWN4-GFP leads to larger, more elongated nuclei in pavement cells, suggesting a tight correlation between CRWN protein abundance and nuclear size [29••].

\section{Nuclear shape and LINC complexes}

Linker of nucleoskeleton and cytoskeleton (LINC) complexes span the INM and the outer nuclear membrane (ONM), forming a nucleocytoplasmic protein bridge [reviewed in 31]. In the NE lumen, INM SUN proteins interact via their C-terminal SUN domains with the Cterminal tails of ONM KASH-domain proteins. Some SUN proteins interact with nuclear lamins. KASH proteins interact directly or indirectly with actin, microtubules or intermediate filaments. Animal LINC complexes have been connected to a variety of developmental events that involve nuclear movement and nuclear positioning [reviewed in 1,31]. In human fibroblasts a dominant-negative KASH fragment eliminates the sensitivity of nuclear shape to substrate rigidity, and this effect could be mimicked by myosin inhibition, suggesting that nuclear shape is modulated by a connection of LINC complexes to actinomyosin tension [32]. Overexpression of different fragments of the giant KASH- 
domain protein Nesprin-2 either increases or decreases nuclear size and the interaction of Nesprin-2 with Nesprin-3 is involved in this size regulation [33].

SUN proteins are conserved between animals and plants, while plant KASH proteins are distinct from their animal counterparts [10••,34,35, reviewed in 36]. Arabidopsis and maize SUN1 and SUN2 are C-terminal SUN domain proteins, and form LINC complexes with plant KASH proteins $[10 \bullet \bullet, 34,35]$. There is also evidence that SUN1 and SUN2 may bind CRWN1 in planta [37]. Trichomes and root hair nuclei of sun1 null mutants are spherical, while sun2 mutants have wildtype-like elongated nuclei in the same cell types [38]. In a sun1 sun2 severe knockdown mutant, root hair nuclei are spherical, and never elongate during development [39,40•]. Arabidopsis also has three mid-SUNs - SUN3, SUN4, and SUN5 - characterized by multiple transmembrane domains and a SUN domain in the center of the protein $[35,41 \bullet, 42]$. sun3 mutant plants' root epidermal cell nuclei are more spherical than WT and lack membrane tails [41•]. Single sun4 or sun5 mutants have no phenotype, but a sun4 sun5 double mutant has smaller nuclei [41•]. The maize mutant desynaptic has spherical nuclei in anthers, and while the locus has not been mapped, a likely candidate is the maize homolog of SUN3 [42].

The most recently identified plant KASH protein is AtTIK, mutants of which have smaller nuclei than WT [41•]. The most extensively characterized Arabidopsis KASH proteins are WIP1, WIP2, and WIP3 [10••,36], which complex with another ONM protein family, WIT1 and WIT2, to form a SUN-WIP-WIT LINC complex (Fig. 2) [10••]. wit1 and sun2 single mutants, as well as wip1 wip2 wip3 (wit123) and wit1 wit2 (wit12) null and sun1 sun2 severe knockdown mutants result in spherical root hair and trichome nuclei [40•]. wit12 further exhibits decreased velocity of nuclear movement in mature root hairs and defective high-light avoidance recovery in leaf mesophyll cells [43••].

wit12 and wip123 mutants, as well as expression of a dominant-negative SUN domain, also lead to reduced VN velocity in growing pollen tubes. In this case, however, no shape or size change of the VN was observed $[38,44]$. The pollen vegetative nucleus narrows during WT pollen tube germination and elongation. While treatment of Galanthus nivalis pollen tubes with the microtubule polymerization inhibitor colchicine does not affect this narrowing, treatment of Lilium henryi pollen tubes with the actin polymerization inhibitor cytochalasin D causes the VN to shorten considerably $[45,46]$. Together, the mutant and drug treatment data suggest that the WIT-WIP-SUN LINC complex at the VN acts via a microtubule- 
dependent mechanism to effect VN movement, and that additional factors that connect the VN to actin are involved in determining its elongated shape during WT development.

\section{Nuclear shape and the cytoskeleton}

During differentiation of mouse and human embryonic stem cells, a LINC complexassociated actin meshwork at the nuclear periphery called the perinuclear actin cap forms and progressively shapes the nucleus $[47,48]$. In HaCaT cells, actin depolymerization reduces nuclear size, MT depolymerization increases it, and a combination of both drugs decreases nuclear size, suggesting that actin plays a dominant role [33].

KAKU1 (MyoXI-i) was identified in a forward-genetic screen for nuclear shape mutants. MyoXI-i is a member of the plant-specific Myosin XI family, which has 13 members in Arabidopsis. Single mutants in all Myosin XIs were tested for nuclear shape and the myoxi-i mutant is the only one that leads to spherical nuclei. A MyoXI-i " $\Delta$ motor" fragment fused to GFP decorates the NE. Interaction proteomics with this fragment identified the plant LINC complex component WIT2. The authors show that MyoXI-i $\Delta$ motor binds the closely related protein WIT1, which in turn binds the plant KASH protein WIP1, which interacts with INM proteins SUN1 and SUN2 [43••].

In a related set of experiments, Zhou et al. [40•] dissected this complex's components further. They established that: 1. SUN1, but not SUN2 and WIT2, but not WIT1 are required for elongated nuclear shape in root epidermal cells, 2. WIT2 interacts with WIP1, WIP2, and WIP3. MyoXI-i association with the NE is diminished in sun1 sun2 severe knockdown and wit2 mutants, but not wit1 mutants. Together, these data imply that MyoXI-i is associated with the NE in root epidermal cells through interactions with a WIT2-WIP-SUN1 complex, and that this complex is required - by an unknown mechanism - to establish the elongated nuclear shape of differentiated root and leaf epidermal cells.

Interestingly, myoxi-i exhibits nuclear movement phenotypes similar to wit12, including decreased nuclear movement in mature root hairs and defective high light avoidance recovery in mesophyll cells. However, no pollen tube nuclear movement defects have been reported. This suggests that the function of MyoXI-i as part of shape- and movementcontrolling LINC complexes is limited to the sporophyte.

\section{Nuclear shape and the nuclear pore}


Thirty Arabidopsis nucleoporins (Nups) have been identified through interactive proteomics, most of which are homologs of yeast or mammalian Nups [49]. However, one plant-specific FG-repeat Nup (Nup136) was also identified (also named Nup1 by [50]). In nup136 mutants, leaf epidermal nuclei are more spherical than in WT and overexpression of Nup136 leads to elongated guard cell nuclei with membrane tails, and over-elongated nuclei in trichomes and leaf epidermal cells [51].

nup136 mutant plants have defects in flowering time, seed set, pollen germination, and mRNA nuclear export. Similar whole-plant and mRNA export phenotypes also occur in other Arabidopsis Nup mutants [52,53,54,55], but in these cases no altered nuclear morphology has been reported. This suggests that Nup136 plays an additional role. Consistently, the most drastic nuclear shape changes occur during Nup136 overexpression, but these plants have no whole-plant phenotypes.

Nucleocytoplasmic transport regulates nuclear size in both Xenopus laevis and Tetrahymena. In Xenopus, nuclear Lamin B is one of the important cargoes and the nucleargrowth defect of import-defective nuclei could be rescued by re-addition of recombinant Lamin B3 [56]. In Tetrahymena, import of histone $\mathrm{H} 1$ affects nuclear size, and different $\mathrm{H} 1$ isoforms are specifically imported into the micro- and the macronucleus [3]. Depletion of Xenopus Nup188, which is dispensable for NPC formation, increases nuclear size. This is caused by an accelerated translocation of integral membrane proteins through NPCs [57]. No nuclear import studies have been performed in nup136 mutants, and testing nuclear abundance and localization of CRWN proteins would be a logical next step.

Nup136 is proposed to be the functional analog of animal Nup153 [49,51]. Nup153 connects to the nuclear lamina in Drosophila and C. elegans and controls spatial distribution of nuclear pore complexes (NPCs) $[58,59,60]$. No correlation between NPC numbers and nuclear size or shape has been found in opisthokonts [61,62], but it would nevertheless be valuable to investigate NPC abundance and distribution in nup136 mutants. In addition, it would be interesting to establish if NUP136 interacts with CRWN1 or CRWN4, because such an interaction would suggest that a structure similar to the porelamina connection in animals has also evolved in plants.

\section{Forward genetic screens for nuclear shape mutants}


An EMS mutant screen for altered nuclear shape identified several $K A K U$ genes, among them KAKU1 (MyoXI-i; discussed above), KAKU4 and KAKU2 (CRWN1). KAKU4 is a plantunique protein with a predicted NLS, no predicted transmembrane domain, and no other domain similarities other than a potential long alpha-helical domain $[63 \bullet \bullet, 64]$. KAKU4 is located at the INM, where it interacts with CRWN1. kaku4 and crwn1 mutants have smooth and spherical nuclei, unlike the kaku1 mutant nuclei, which are spherical and irregularly invaginated. KAKU4 overexpression leads to deformation and overproliferation of the NE, including substantial invaginations, additional ring-like NE structures inside the nucleus, stacked NE without nuclear pores, and extranuclear membrane whorls [63••]. KAKU4 overexpression in a crwn1 mutant leads to similar effects including ring- and bleb-like structures as well as long KAKU4-GFP-labeled "tails" extruding from the spherical nuclei, suggesting that the KAKU4-based membrane deformation does not require CRWN1. Nevertheless, co-overexpression of KAKU4 and CRWN1 had the most striking effect, leading to numerous spherical structures filling the nucleus. These data suggest that proteins located at the NE could play a role in regulation of the amount of NE membranes present around chromatin. It would be interesting to determine the identity of the additional membrane in the KAKU4 overexpressing mutants - could a loss of distinction between NE and ER identity result in additional ER membrane accumulating around the chromatin? Anderson and Hetzer [65] showed that overexpression of the ER tubuleforming proteins inhibited NE formation and nuclear expansion, suggesting that the transition from membrane tubules to sheets is rate-limiting for nuclear assembly in mammalian cells.

Several opisthokont INM proteins are also implicated in nuclear shape regulation. Depletion of lamin B receptor (LBR) causes hypo-lobulated nuclei, a truncated laminaassociated polypeptide 2 isoform $\beta$ (Lap2 $\beta$ ) fragment reduces nuclear size and depletion of C. elegans Ankyrin repeat and LEM domain-containing protein 2 homolog (LEM4) causes misshapen, multilobed nuclei [1]. The INM-associated protein complement appears to be not deeply conserved, and most opisthokont INM-associated proteins have no structural plant homologs [38].Thus, KAKU4 is an exciting candidate for an INM protein activity possibly functionally, but not structurally, conserved across supergroups.

\section{Nuclear shape and mitosis}


The events that re-form the NE at the end of open mitosis can be important to establish normal interphase nuclear morphology [66]. For example, depletion of the chromatinbinding protein developmental pluripotency associated 2 (Dppa2) from Xenopus egg extracts leads to the formation of small, misshapen nuclei, likely through defects in the regulation of microtubule polymerization during NE reformation [67].

In plants, which lack centrosomes, the NE plays a role as the microtubule organizing center (MTOC) at the onset of mitosis. Gamma-tubulin complexes ( $\gamma$-TuCs) are recruited to the NE and contribute to the establishment of the mitotic spindle $[68,69]$. One of the $\gamma$-TuC core subunits, $\gamma$-tubulin complex protein 3 (GCP3), binds GCP3 interacting proteins 1 and 2 (GIP1 and GIP2), two $8 \mathrm{kD}$ alpha-helical proteins [70•]. GIP homologues were first seen in humans and, more recently, in S. pombe where they are known as mitotic spindleorganizing protein 1 (MZT1) [70•,71,72]. Arabidopsis GIP1 and GIP2 co-localize with both chromocenters at the INM and MTs at the ONM [73], and are required for centromere architecture. In their absence, recruitment of critical centromere proteins is altered and centromere assembly and cohesion are affected [74]. gip1 gip2 double mutants have a variety of developmental defects, including germination and flowering defects, corkscrewlike root growth, short hypocotyls and bulging, irregularly shaped root meristem cells $[70 \bullet]$.

Root tip cells of gip1 gip2 double mutants have massively enlarged nuclei with distorted shapes, a loss of circularity, and an increase in ploidy. In addition, there are lobulated and highly dented nuclei in various differentiated cells [71]. NPC density was increased and the distribution of the NE marker Arabidopsis SUN1 was altered, suggesting an overall disturbance of NE composition.

\section{Conclusions}

Like in animals, proteins involved in regulating nuclear shape and size in plants center at the NE (Fig. 2, Table 1). Some players, such as the SUN proteins, are highly conserved, while in other cases functional analogs with little or no sequence or structural similarities have evolved. At least two independent shape-determining pathways have been dissected: one involving a WIT2-WIP-SUN1 LINC complex and leading to spherical nuclei with invaginated membranes, and a second involving the lamin-like protein CRWN1, leading to spherical nuclei with a smooth, minimal NE. This supports a model of nuclei being shaped both by 
cytoplasmic forces transferred to the NE and by nucleoplasmic filaments formed under the NE. It also suggests that disruption of some pathways leads to loss of control over the balance between nuclear volume and NE membrane abundance, while in other cases, this balance remains under control.

While not all nuclear size and shape mutants have been tested for nuclear movement, there are interesting correlations of loss of nuclear elongation and reduced velocity of movement (Table 1) [reviewed in 75]. Though this elongated shape does not occur in all plant cells with mobile nuclei, it is tempting to speculate that the elongated shape is energetically advantageous for nuclear movement through a dense cytoplasm, and that movement is decelerated in such mutants that don't allow for the most streamlined shape to form. An alternative model could be that the forces of movement themselves cause the elongated shape. This, however, seems less likely, because isolated nuclei retain their elongated shape in vitro [29••].

There is a need for a better mechanistic understanding of nuclear size and shape regulation, including dissecting lipid homeostasis at the $\mathrm{NE}$, connections to chromatin organization, the connection between shape and movement, and the biomechanics of the NE. Plants appear to tolerate several drastic nuclear shape and size changes without obvious deleterious effects on growth and development and might thus emerge as a robust model system to dissect the underlying molecular mechanisms that are currently unknown in any system.

\section{Acknowledgements}

We apologize to all colleagues whose work could not be included due to length constraints and would like to thank Mr. Andrew Kirkpatrick for critical reading of the manuscript. Our work in this field is supported by grants from the National Science Foundation to I.M.

\section{Figure legends}

Figure 1. Graphical depictions of nuclear shapes in different Arabidopsis cell types.

(A) Nuclei in petal vascular tissue are rod- and oval-shaped [9].

(B) Trichome nuclei are large and oval-shaped [9].

(C) Root hair nuclei adopt a range of shapes during development and after differentiation. Nuclei in elongating root hairs tend to be oval (bottom). Nuclei in mature root hairs can adopt a range of shapes. From top to second from bottom: flattened, with tails [9]; spindle- 
shaped [9]; and multiple connected subnuclear structures [9].

(D) Root meristem nuclei are generally spherical.

(E) Root epidermal nuclei are spindle-shaped.

(F) Nuclear shape in leaf cells varies between cell types. Nuclei in guard cells and mesophyll cells tend to be spherical. Pavement (epidermal) cell nuclei can be either ellipsoid or spherical.

(G) In mature pollen, the vegetative nucleus (purple) is highly invaginated, including a channel that facilitates attachment to the cytoplasmic projections (grey) of the sperm cells (their spherical nuclei shown in blue) [14,15].

(H) In germinated Arabidopsis pollen, the sperm cells (spherical to oval nuclei shown in blue) are connected to each other and the vegetative nucleus (purple) by cytoplasmic projections (grey) $[14,16,44]$. The nucleus elongates during pollen germination, and is oblong in shape, with some invagination $[14,16,45]$.

Figure 2: Proteins that play a role in plant nuclear envelope (NE) shape determination. From left to right: CRWN1 and CRWN4 are found at the nuclear periphery, near the inner nuclear membrane (INM), while CRWN2 and CRWN3 are restricted to the interior of the nucleus $[26,29 \bullet \bullet]$. GCP3 interacting proteins (GIPs) are distributed throughout the NE and associated near the nuclear pore complex (NPC) at both the outer nuclear membrane (ONM) and INM [71]. At the ONM GIPs associate with microtubule organizing center (MTOC) whereas at the INM they localize with chromocenters [74]. Nup136, a plantspecific FG-repeat nucleoporin, is part of the NPC located near the INM [49]. WIP, an Arabidopsis KASH protein, located at the ONM binds to INM protein SUN3 (a mid-SUN protein) and SUN1 and SUN2 (C-terminal SUN proteins) $[10 \bullet \bullet, 41 \bullet, 54 \bullet \bullet]$. WIPs also bind to the ONM-associated WIT proteins to form a complex with Myosin XI-i and actin filaments [43••]. SUN1 and SUN2 binds CRWN1 whereas SUN3 binds TIK, another plant KASH protein $[37,41 \cdot]$. TIK further binds to SUN1, SUN2 and SUN4, another mid-sun protein (not shown) [41•]. KAKU4 located near the INM and was found to be associated with CRWN1 [63・•]. Additionally, mid-SUNs interact with each other as well as with the C-terminal SUN proteins (not shown) [41•]. * Interactions only supported by one type of experiment. 
References and recommended reading

- of special interest

$\bullet$ of outstanding interest

1. Jevtić P, Edens LJ, Vuković LD, Levy DL: Sizing and shaping the nucleus: mechanisms and significance. Curr Opin Cell Biol 2014, 28:16-27.

2. Chow K-H, Factor RE, Ullman KS: The nuclear envelope environment and its cancer connections. Nat Rev Cancer 2012, 12:196-209.

3. Jevtić $P$, Levy DL: Mechanisms of nuclear size regulation in model systems and cancer. Adv Exp Med Biol 2014, 773:537-569.

4. Capell BC, Collins FS: Human laminopathies: nuclei gone genetically awry. Nat Rev Genet 2006, 7:940-952.

5. Mounkes L, Kozlov S, Burke B, Stewart CL: The laminopathies: nuclear structure meets disease. Curr Opin Genet Dev 2003, 13:223-230.

6. Walters AD, Bommakanti A, Cohen-Fix O: Shaping the nucleus: factors and forces. $J$ Cell Biochem 2012, 113:2813-2821.

7. Adl SM, Simpson AG, Lane CE, Lukeš J, Bass D, Bowser SS, Brown MW, Burki F, Dunthorn M, Hampl V: The revised classification of eukaryotes. J Eukaryot Microbiol 2012, 59:429-514.

8. Sugimoto-Shirasu K, Roberts K: "Big it up": endoreduplication and cell-size control in plants. Curr Opin Plant Biol 2003, 6:544-553.

9. Chytilova E, Macas J, Galbraith DW: Green fluorescent protein targeted to the nucleus, a transgenic phenotype useful for studies in plant biology. Ann Bot 1999, 83:645-654.

10. Zhou X, Graumann K, Evans DE, Meier I: Novel plant SUN-KASH bridges are involved in RanGAP anchoring and nuclear shape determination. J Cell Biol 2012, 196:203-211.

• This study defines the first KASH proteins in plants by identifying a C-terminal domain similar in structure to opisthokont KASH domains, and demonstrating binding to Arabidopsis SUN proteins. The authors establish that plants defective in these proteins have nuclear shape defects in root hairs and trichomes.

11. Chytilova E, Macas J, Sliwinska E, Rafelski SM, Lambert GM, Galbraith DW: Nuclear Dynamics in Arabidopsis thaliana. Mol Biol Cell 2000, 11:2733-2741.

12. Guimil S, Dunand C: Cell growth and differentiation in Arabidopsis epidermal cells. J Exp Bot 2007, 58:3829-3840.

13. Borg $\mathrm{M}$, Berger $\mathrm{F}$ : Chromatin remodelling during male gametophyte development. Plant J 2015, 83:177-188.

14. McCue AD, Cresti M, Feijó JA, Slotkin RK: Cytoplasmic connection of sperm cells to the pollen vegetative cell nucleus: potential roles of the male germ unit revisited. J Exp Bot 2011, 62:1621-1631.

15. McConchie CA, Jobson S, Knox RB: Computer-Assisted Reconstruction of the Male Germ Unit in Pollen of Brassical campestris. Protoplasma 1985, 127:57-63.

16. Yu H-S, Hu S-Y, Zhu C: Ultrastructure of sperm cells and the male germ unit in pollen tubes of Nicotiana tabacum. Protoplasma 1989, 152:29-36.

17. van Zanten M, Koini MA, Geyer R, Liu Y, Brambilla V, Bartels D, Koornneef M, Fransz P, Soppe WJJ: Seed maturation in Arabidopsis thaliana is characterized by nuclear size reduction and increased chromatin condensation. Proc Natl Acad Sci U S A 2011, 108:20219-20224. 
• The authors examine nuclear size in embryonic cotyledons during seed development and establish that nuclear size decreases as seed development enters the seed maturation phase. This study determines that a master regulator of seed maturation, $\mathrm{ABI} 3$, also controls nuclear size during maturation. Additionally, mutants in the lamin analogs CRWN1 and CRWN2 fail to recover nuclear size following seed germination.

18. Kater J: A cytological study of dormancy in the seed of Phaseolus vulgaris. Ann Bot 1927, 41:629-642.

19. Middendorf FG: Cytology of dormancy in Phaseolus and Zea. Bot Gaz 1939, 100:485499.

20. Mansfield S, Briarty L: Cotyledon cell development in Arabidopsis thaliana during reserve deposition. Can J Bot 1992, 70:151-164.

21. Finan JD, Guilak F: The effects of osmotic stress on the structure and function of the cell nucleus. J Cell Biochem 2010, 109:460-467.

22. Davidson PM, Lammerding J: Broken nuclei - lamins, nuclear mechanics, and disease. Trends Cell Biol 2014, 24:247-256.

23. Funkhouser CM, Sknepnek R, Shimi T, Goldman AE, Goldman RD, Olvera de la Cruz M: Mechanical model of blebbing in nuclear lamin meshworks. Proc Natl Acad Sci U $S$ A 2013, 110:3248-3253.

24. Fiserova J, Kiseleva E, Goldberg MW: Nuclear envelope and nuclear pore complex structure and organization in tobacco BY-2 cells. Plant J 2009, 59:243-255.

25. Masuda K, Xu ZJ, Takahashi S, Ito A, Ono M, Nomura K, Inoue M: Peripheral Framework of Carrot Cell Nucleus Contains a Novel Protein Predicted to Exhibit a Long $\boldsymbol{\alpha}$-Helical Domain. Exp Cell Res 1997, 232:173-181.

26. Dittmer TA, Stacey NJ, Sugimoto-Shirasu K, Richards EJ: LITTLE NUCLEI Genes Affecting Nuclear Morphology in Arabidopsis thaliana. Plant Cell 2007, 19:27932803.

27. Ciska M, Masuda K, Moreno Díaz de la Espina S: Lamin-like analogues in plants: the characterization of NMCP1 in Allium cepa. J Exp Bot 2013, 64:1553-1564. -This paper describes the bioinformatic analysis and classification of the NMCP (CRWN) family based on phylogenetic relationships. In conjunction with the biochemical characterization of NMCP1 in Allium cepa, the paper shows that NMCPs have many similarities with animal lamins and may fulfil the function of lamins in plants.

28. Ciska M, Moreno Díaz de la Espina S: The intriguing plant nuclear lamina. Front Plant Sci 2014, 5:166.

29. Sakamoto Y, Takagi S: LITTLE NUCLEI 1 and 4 Regulate Nuclear Morphology in Arabidopsis thaliana. Plant Cell Physiol 2013, 54:622-633.

-Used a reverse genetic approach to identify potential plant lamina components CRWN1 and CRWN4. Described ploidy-independent nuclear circularity phenotypes and subcellular localization for all CRWNs, as well as the overexpression phenotype of CRWN4.

30. Wang H, Dittmer TA, Richards EJ: Arabidopsis CROWDED NUCLEI (CRWN) proteins are required for nuclear size control and heterochromatin organization. $B M C$ Plant Biol 2013, 13:200.

-•By performing extensive mutant analysis, this study shows that CRWN proteins are necessary for viability, and that CRWN1 and CRWN4 are the primary determinants of nuclear shape and size among the CRWN proteins. It further 
discusses a decrease in crwn 4 mutant chromocenters that correlates with a decrease in nuclear size.

31. Starr DA, Fridolfsson HN: Interactions between nuclei and the cytoskeleton are mediated by SUN-KASH nuclear-envelope bridges. Annu Rev Cell Dev Biol 2010, 26:421-444.

32. Lovett DB, Shekhar N, Nickerson JA, Roux KJ, Lele TP: Modulation of Nuclear Shape by Substrate Rigidity. Cell Mol Bioeng 2013, 6:230-238.

33. Lu W, Schneider M, Neumann S, Jaeger V-M, Taranum S, Munck M, Cartwright S, Richardson C, Carthew J, Noh $\mathrm{K}$, et al.: Nesprin interchain associations control nuclear size. Cell Mol Life Sci 2012, 69:3493-3509.

34. Graumann K, Runions J, Evans DE: Characterization of SUN-domain proteins at the higher plant nuclear envelope. Plant J 2010, 61:134-144.

35. Murphy S, Simmons C, Bass H: Structure and expression of the maize (Zea mays L.) SUN-domain protein gene family: evidence for the existence of two divergent classes of SUN proteins in plants. BMC Plant Biology 2010, 10:269.

36. Zhou X, Graumann $\mathrm{K}$, Meier I: The plant nuclear envelope as a multifunctional platform LINCed by SUN and KASH. J Exp Bot 2015, 66:1649-1659.

37. Graumann K: Evidence for LINC1-SUN Associations at the Plant Nuclear Periphery. PLoS ONE 2014, 9:e93406.

38. Zhou X, Groves NR, Meier I: SUN anchors pollen WIP-WIT complexes at the vegetative nuclear envelope and is necessary for pollen tube targeting and fertility. J Exp Bot 2015, 66:7299-7307.

39. Oda Y, Fukuda H: Dynamics of Arabidopsis SUN proteins during mitosis and their involvement in nuclear shaping. Plant J 2011, 66:629-641.

40. Zhou X, Groves NR, Meier I: Plant nuclear shape is independently determined by the SUN-WIP-WIT2-myosin XI-i complex and CRWN1. Nucleus 2015, 6:144-153. -Dissects individual contributions of WIT and SUN family members in detemining nuclear shape. Shows that the roles of the respective WIT and SUN paralogs have diverged in trichomes and root hairs and that the SUN-WIP-WIT2-myoXI-i complex and CRWN1 independently determine elongated nuclear shape. This supports a model of nuclear shape being determined both by both cytoplasmic forces and nucleoplasmic events.

41. Graumann K, Vanrobays E, Tutois S, Probst AV, Evans DE, Tatout C: Characterization of two distinct subfamilies of SUN-domain proteins in Arabidopsis and their interactions with the novel KASH-domain protein AtTIK. J Exp Bot 2014, 65:6499-6512.

-First characterization of mid-SUNs in Arabidopsis. Identification of a new plant KASH protein (TIK) that binds Cter-SUns and mid-SUNs and is involved in determining nuclear shape.

42. Murphy SP, Bass HW: The maize (Zea mays) desynaptic (dy) mutation defines a pathway for meiotic chromosome segregation, linking nuclear morphology, telomere distribution and synapsis. J Cell Sci 2012, 125:3681-3690.

43. Tamura K, Iwabuchi K, Fukao Y, Kondo M, Okamoto K, Ueda H, Nishimura M, HaraNishimura I: Myosin XI-i Links the Nuclear Membrane to the Cytoskeleton to Control Nuclear Movement and Shape in Arabidopsis. Curr Biol 2013, 23:17761781.

- The authors identify a plant-specific myosin, Myosin XI-i, in a mutant screen for nuclear shape defects. Myosin XI-i mutants have impaired dark-induced nuclear movement, in addition to defects in nuclear shape in trichomes, root hairs and leaf 
epidermal cells, and a nuclear movement defect in root hairs. Myosin XI-i is shown to bind WITs at the NE, and binding is required for its NE association.

44. Zhou X, Meier I: Efficient plant male fertility depends on vegetative nuclear movement mediated by two families of plant outer nuclear membrane proteins. Proc Natl Acad Sci U S A 2014, 111:11900-11905.

45. Heslop-Harrison J, Heslop-Harrison Y, Cresti M, Tiezzi A, Moscatelli A: Cytoskeletal elements, cell shaping and movement in the angiosperm pollen tube. J Cell Sci 1988, 91:49-60.

46. Heslop-Harrison J, Heslop-Harrison Y: Conformation and movement of the vegetative nucleus of the angiosperm pollen tube: association with the actin cytoskeleton. J Cell Sci 1989, 93:299-308.

47. Khatau SB, Kusuma S, Hanjaya-Putra D, Mali P, Cheng L, Lee JSH, Gerecht S, Wirtz D: The Differential Formation of the LINC-Mediated Perinuclear Actin Cap in Pluripotent and Somatic Cells. PLoS ONE 2012, 7:e36689.

48. Khatau SB, Hale CM, Stewart-Hutchinson PJ, Patel MS, Stewart CL, Searson PC, Hodzic D, Wirtz D: A perinuclear actin cap regulates nuclear shape. Proc Natl Acad Sci U S A 2009, 106:19017-19022.

49. Tamura K, Fukao Y, Iwamoto M, Haraguchi T, Hara-Nishimura I: Identification and Characterization of Nuclear Pore Complex Components in Arabidopsis thaliana. Plant Cell 2010, 22:4084-4097.

50. Lu Q, Tang X, Tian G, Wang F, Liu K, Nguyen V, Kohalmi SE, Keller WA, Tsang EW, Harada JJ: Arabidopsis homolog of the yeast TREX - 2 mRNA export complex: components and anchoring nucleoporin. Plant J 2010, 61:259-270.

51. Tamura K, Hara-Nishimura I: Involvement of the nuclear pore complex in morphology of the plant nucleus. Nucleus 2011, 2:168-172.

52. Muthuswamy S, Meier I: Genetic and environmental changes in SUMO homeostasis lead to nuclear mRNA retention in plants. Planta 2011, 233:201-208.

53. Parry G, Ward S, Cernac A, Dharmasiri S, Estelle M: The Arabidopsis SUPPRESSOR OF AUXIN RESISTANCE Proteins Are Nucleoporins with an Important Role in Hormone Signaling and Development. Plant Cell 2006, 18:1590-1603.

54. Xu XM, Rose A, Muthuswamy S, Jeong SY, Venkatakrishnan S, Zhao Q, Meier I: NUCLEAR PORE ANCHOR, the Arabidopsis Homolog of Tpr/Mlp1/Mlp2/Megator, Is Involved in mRNA Export and SUMO Homeostasis and Affects Diverse Aspects of Plant Development. Plant Cell 2007, 19:1537-1548.

55. Zhang Y, Li X: A Putative Nucleoporin 96 Is Required for Both Basal Defense and Constitutive Resistance Responses Mediated by suppressor of npr11,constitutive 1. Plant Cell 2005, 17:1306-1316.

56. Levy DL, Heald R: Nuclear Size Is Regulated by Importin $\alpha$ and Ntf2 in Xenopus. Cell 2010, 143:288-298.

57. Theerthagiri G, Eisenhardt N, Schwarz H, Antonin W: The nucleoporin Nup188 controls passage of membrane proteins across the nuclear pore complex. $\mathrm{J}$ Cell Biol 2010, 189:1129-1142.

58. Liu J, Ben-Shahar TR, Riemer D, Treinin M, Spann P, Weber K, Fire A, Gruenbaum Y: Essential Roles for Caenorhabditis elegans Lamin Gene in Nuclear Organization, Cell Cycle Progression, and Spatial Organization of Nuclear Pore Complexes. Mol Biol Cell 2000, 11:3937-3947.

59. Smythe C, Jenkins HE, Hutchison CJ: Incorporation of the nuclear pore basket protein Nup153 into nuclear pore structures is dependent upon lamina 
assembly: evidence from cell - free extracts of Xenopus eggs. EMBO J 2000, 19:3918-3931.

60. Walther TC, Fornerod M, Pickersgill H, Goldberg M, Allen TD, Mattaj IW: The nucleoporin Nup153 is required for nuclear pore basket formation, nuclear pore complex anchoring and import of a subset of nuclear proteins. $E M B O \mathrm{~J}$ 2001, 20:5703-5714.

61. Maeshima K, Iino H, Hihara S, Funakoshi T, Watanabe A, Nishimura M, Nakatomi R, Yahata K, Imamoto F, Hashikawa T, et al.: Nuclear pore formation but not nuclear growth is governed by cyclin-dependent kinases (Cdks) during interphase. Nat Struct Mol Biol 2010, 17:1065-1071.

62. Maul GG, Deaven LL, Freed JJ, Campbell GLM, Beçak W: Investigation of the determinants of nuclear pore number. Cytogenet Genome Res 1980, 26:175-190.

63. Goto C, Tamura K, Fukao Y, Shimada T, Hara-Nishimura I: The Novel Nuclear Envelope Protein KAKU4 Modulates Nuclear Morphology in Arabidopsis. Plant Cell 2014, 26:2143-2155.

••An innovative EMS mutant screen identified a novel protein involved in nuclear shape determination, KAKU4. This study establishes that KAKU4 is associatedwith the INM and that it interacts physically and genetically with CRWN1. KAKU4 overexpression deforms the NE in a dose-dependent manner and creates membrane deformations and membrane stacks.

64. Källberg M, Wang H, Wang S, Peng J, Wang Z, Lu H, Xu J: Template-based protein structure modeling using the RaptorX web server. Nat Protocols 2012, 7:15111522.

65. Anderson DJ, Hetzer MW: Reshaping of the endoplasmic reticulum limits the rate for nuclear envelope formation. J Cell Biol 2008, 182:911-924.

66. Schooley A, Vollmer B, Antonin W: Building a nuclear envelope at the end of mitosis: coordinating membrane reorganization, nuclear pore complex assembly, and chromatin de-condensation. Chromosoma 2012, 121:539-554.

67. Xue John Z, Woo Eileen M, Postow L, Chait Brian T, Funabiki H: Chromatin-Bound Xenopus Dppa2 Shapes the Nucleus by Locally Inhibiting Microtubule Assembly. Dev Cell 2013, 27:47-59.

68. Binarová P, Cenklová V, Procházková J, Doskočilová A, Volc J, Vrlík M, Bögre L: $\boldsymbol{\gamma}$ Tubulin Is Essential for Acentrosomal Microtubule Nucleation and Coordination of Late Mitotic Events in Arabidopsis. Plant Cell 2006, 18:11991212.

69. Liu B, Marc J, Joshi HC, Palevitz BA: A gamma-tubulin-related protein associated with the microtubule arrays of higher plants in a cell cycle-dependent manner. J Cell Sci 1993, 104:1217-1228.

70. Janski N, Masoud K, Batzenschlager M, Herzog E, Evrard J-L, Houlné G, Bourge M, Chabouté M-E, Schmit A-C: The GCP3-interacting proteins GIP1 and GIP2 are required for $\boldsymbol{\gamma}$-tubulin complex protein localization, spindle integrity, and chromosomal stability. Plant Cell 2012, 24:1171-1187.

-Foundational study employing a combination of yeast two-hybrid, in-vitro analysis, and Co-IP assays to demonstrate interactions between GIP1/2 and GCP3 as well as GIP1, GCP3, and gamma-tubulin. Reveals enlarged and misshapen nuclei in gip1gip2 double mutants

71. Batzenschlager M, Masoud K, Janski N, Houlné G, Herzog E, Evrard J-L, Baumberger N, Erhardt M, Nominé Y, Kieffer B, et al.: The GIP gamma-tubulin complex- 
associated proteins are involved in nuclear architecture in Arabidopsis thaliana. Front Plant Sci 2013, 4:480.

72. Janski N, Herzog E, Schmit A-C: Identification of a novel small Arabidopsis protein interacting with gamma-tubulin complex protein 3. Cell Biol Int 2008, 32:546548.

73. Batzenschlager M, Herzog E, Houlné G, Schmit A-C, Chabouté M-E: GIP/MZT1 proteins orchestrate nuclear shaping. Front Plant Sci 2014, 5:29.

74. Batzenschlager M, Lermontova I, Schubert V, Fuchs J, Berr A, Koini MA, Houlné G, Herzog E, Rutten T, Alioua A, et al.: Arabidopsis MZT1 homologs GIP1 and GIP2 are essential for centromere architecture. Proc Natl Acad Sci U S A 2015, 112:8656-8660.

75. Griffis AHN, Groves NR, Zhou X, Meier I: Nuclei in motion: movement and positioning of plant nuclei in development, signaling, symbiosis, and disease. Front Plant Sci 2014, 5:1-7. 
Figure 1
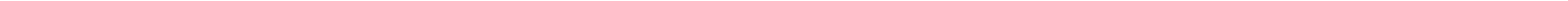

1 


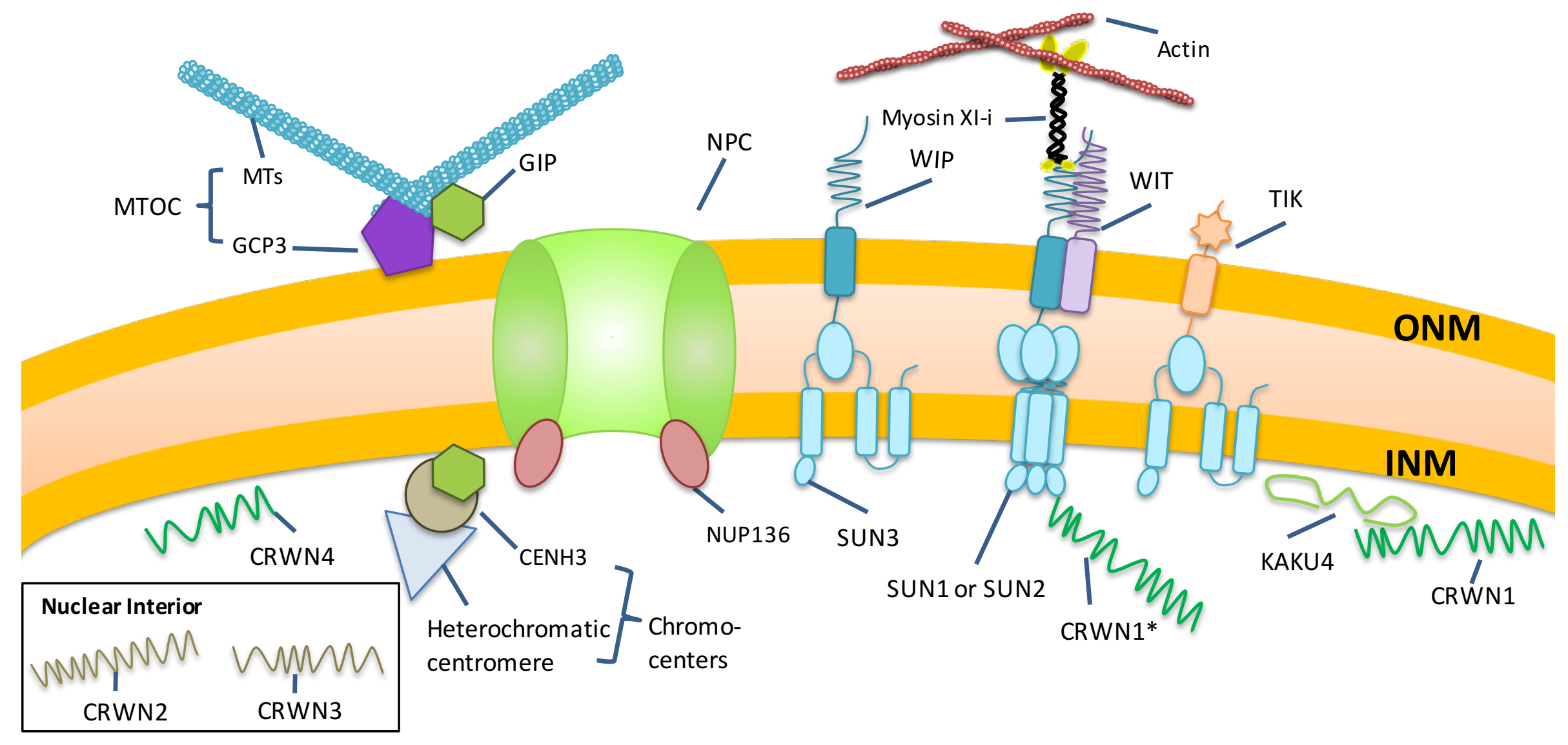


Table 1

Mutants and treatments that affect nuclear shape and movement in plants

Protein Organism(s) Function

Nuclear Shape

Nuclear Movement

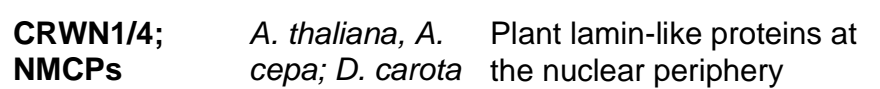
NMCPs

$\begin{array}{lll}\text { CRWN2/3 A. thaliana } & \begin{array}{l}\text { Plant lamin-like proteins in } \\ \text { the nucleoplasm }\end{array}\end{array}$

KAKU4 A. thaliana Nuclear periphery-localized

protein of unknown function

$\begin{array}{lll}\text { SUN1/2 } & \text { A. thaliana } & \begin{array}{l}\text { C-terminal SUN domain } \\ \text { proteins; INM components of } \\ \text { plant LINC complexes }\end{array}\end{array}$

\begin{tabular}{lll}
\hline SUN3/4/5 & $\begin{array}{l}\text { A. thaliana, Z. } \\
\text { mays }\end{array}$ & $\begin{array}{l}\text { Mid-SUN domain proteins; } \\
\text { localized to the INM }\end{array}$ \\
\hline GIP1/2/3 & A. thaliana & $\begin{array}{l}\text { Localized to microtubule } \\
\text { organizing centers near the } \\
\text { ONM and chromocenters } \\
\text { near the INM }\end{array}$ \\
\hline WIP1/2/3 & A. thaliana & $\begin{array}{l}\text { Plant KASH proteins; ONM } \\
\text { components of plant LINC } \\
\text { complexes }\end{array}$ \\
\hline
\end{tabular}

WIT1/2 A. thaliana

TIK A. thaliana

Myosin XI family member;

\begin{tabular}{lll} 
Myosin XI-i A. thaliana $\quad \begin{array}{l}\text { Myosin XI family member; } \\
\text { associates with the SUN/WIP } \\
\text { LINC complex. }\end{array}$ \\
\hline
\end{tabular}

ONM protein that connects RanGAP and Myosin XI-I to the SUN/WIP LINC complex

LINC complex.

Plant KASH protein localized tik: decrease in nuclear size in root epidermal cells [41•].

crwn1; crwn4: SSN in trichomes and

leaf epidermal cells $[26,29 \bullet \bullet, 30 \bullet \bullet]$.

crwn1 crwn2; crwn1 crwn3: Enhanced

SSN phenotype in trichomes and leaf epidermal cells $[26,29 \bullet \bullet, 30 \bullet \bullet]$.

kaku4: SSN in leaf epidermal and root cells. KAKU4 OX: Invaginated nuclei and ring-like structures [63••]

sun1-KO sun2-KD: $\mathrm{SpN}$ in trichomes, leaf epidermal cells. Spherical, invaginated nuclei in root hairs. Elonglated shape of pollen VN not affected $[10 \bullet \bullet, 38,39,40 \bullet, 44]$.

A dominant-negative SUN2 fragment leads to reduced velocity of VN migration through the pollen tube [38]. sun3: $\mathrm{SpN}$ in root epidermal cells. sun4

sun5: Small nuclei in root epidermal cells [41•].

gip1 gip2: Enlarged, lobulated nuclei.

Increased nuclear pore size and density $[70 \bullet, 71,73]$.

wip1 wip2 wip3: SpN in trichomes, leaf epidermal cells and root hairs. Elonglated shape of pollen VN not affected $[10 \bullet \bullet, 44]$.

wit2; wit1 wit2: $\mathrm{SpN}$ in trichomes and leaf epidermal cells. Spherical, invaginated nuclei in root hairs. Elonglated shape of pollen $\mathrm{VN}$ not affected $[10 \bullet \bullet, 40 \bullet, 43 \bullet \bullet, 44]$.

wip1 wip2 wip3: reversed VN/SN nuclear order in growing pollen tubes [44].

wit1 wit2: Reduced velocity of VN through the pollen tube. wit1 wit2: delays recovery after high-light avoidance movement of leaf epidermal nuclei $[43 \bullet \bullet, 44]$.

myosin $x i-i: \mathrm{SpN}$ in root epidermal cells $[43 \bullet \bullet]$.

myosin xi-i: delays recovery after high-light avoidance movement of leaf epidermal nuclei [43••].

\begin{tabular}{lll}
\hline Nup136 A. thaliana & $\begin{array}{l}\text { Nucleoporin; FG-repeat } \\
\text { protein of the nuclear pore } \\
\text { complex. }\end{array}$ \\
\hline
\end{tabular}

\begin{tabular}{rll}
\hline Filament & Organism(s) & \multicolumn{1}{c}{ Treatment(s) } \\
\hline \multirow{2}{*}{ Actin } & $\begin{array}{ll}\text { L. henryi; } A . \\
\text { thaliana }\end{array}$ & $\begin{array}{l}\text { Cytochalasin D, Cytochalasin } \\
\text { B, Latrunculin B , N- } \\
\text { ethylmaleimide }\end{array}$ \\
\hline
\end{tabular}

\section{L. henryi; $A$.} thaliana; $M$.

$\begin{array}{lll}\text { L. henryi; } A . & & \\ \text { thaliana; } M . & \text { Taxol, Oryzalin, Vinblastine, } & \begin{array}{l}\text { Disruption of the microtubule network } \\ \text { had no effect in root cells and pollen } \\ \text { truncatula; } N .\end{array} \\ \begin{array}{l}\text { tabacum; } N . \\ \text { alata }\end{array} & \text { Colchicine } & \end{array}$

\begin{abstract}
nup136: SpN in leaf epidermal cells.
NUP136 OX: EN in guard cells, and exascerbated EN in trichomes and leaf epidermal cells [49,51].
\end{abstract}

Nuclear Shape

Disruption of the actin network leads to a decrease in pollen tube $\mathrm{VN}$ length $[11,46]$
Disruption of the actin network leads to a reduction or elimination of root hair nuclear movement $[11,75]$

Disruption of the microtubule network increased nuclear distance from the root hair tip in Medicago, but not Arabidopsis. In pollen tubes, disruption of the microtubule network reversed VN/SN order and stunted nuclear movement $[11,45,75]$ had no effect in root cells and pollen tubes $[11,45]$ Overexpression. Protein names belonging to a single family have been abbreviated to save space, such as SUN3/4/5 = SUN3, SUN4, and SUN5. 